\title{
Preferential sorption of tannins at aluminum oxide affects the electron exchange capacities of dissolved and sorbed humic acids fractions
}

\author{
Edisson Subdiaga ${ }^{1}$, Mourad Harir $^{2,3 *}$, Silvia Orsetti ${ }^{1}$, Norbert Hertkorn ${ }^{2}$, \\ Philippe Schmitt-Kopplin ${ }^{2,3}$, Stefan B. Haderlein ${ }^{1 *}$
}

${ }^{1}$ Environmental Mineralogy and Chemistry, Center for Applied Geosciences, University of Tübingen, Hölderlinstr. 12, D-72074 Tübingen, Germany

2 Helmholtz Zentrum München, Research Unit Analytical BioGeoChemistry, Ingolstädter Landstraße 1, 85764 Neuherberg, Germany

${ }^{3}$ Technische Universität München, Lehrstuhl für Analytische Lebensmittelchemie, Maximus-von-Imhof-Forum 2, 85354 Freising, Germany

Corresponding Authors:

* Phone: +49 07071 2973148; e-mail: haderlein@uni-tuebingen.de

* Phone: +49 089 31873775; e-mail: mourad.harir@helmholtz-muenchen.de

\section{Content}

Table S-1

S-2

Table S-2

$\mathrm{S}-3$

Table S-3

S-4

Figure S-1

S-5

Figure S-2

S-6

Figure S-3

S-7,8,9

Figure S-4

S-10,11,12

Figure S-5

S-13

Figure S-6

S-14

Figure S-7

S-15

Figure S-8

S-16

Figure S-9 
Table S-1. Humic Acid to sorbent ratios in batch sorption experiments conducted with hydrophobic resin (DAX-8) and aluminum oxide $\left(\mathrm{Al}_{2} \mathrm{O}_{3}\right)$ sorbents for Elliott Soil (ESHA), Pahokee Peat (PPHA) and Suwannee River (SRHA) humic acids. $\mathrm{HA}_{\mathrm{aq}}\left(\mathrm{mg} \mathrm{C} * \mathrm{~L}^{-1}\right.$ ) refers to the DOC remaining in solution after sorption (mean \pm standard deviation; $n \geq 4$ ). $\mathrm{HA}_{\text {sorb }}$ corresponds to concentration of adsorbed HA per sorbent mass. \% sorbed HA indicates the percentage of sorbed HA based on the total amount of HA in the system. DAX-8 sorbent is highlighted in light orange and $\mathrm{Al}_{2} \mathrm{O}_{3}$ sorbent in light green.

\begin{tabular}{|c|c|c|c|c|}
\hline $\begin{array}{l}\text { Experimental } \\
\text { Setup }\end{array}$ & $\begin{array}{l}\text { Mass ratio } \\
\text { HA/sorbent }\end{array}$ & $\begin{array}{c}\mathbf{H A}_{\mathrm{aq}} \\
{[\mathrm{mg} \mathrm{C} / \mathrm{L}]}\end{array}$ & $\begin{array}{c}\text { Sorbed HA } \\
\text { [mg C/g sorbent] }\end{array}$ & $\%$ sorbed HA \\
\hline S1-SRHA-DAX-8 & $1 / 125$ & $16 \pm 1$ & $0.7 \pm 0.2$ & $11 \pm 3$ \\
\hline S2-SRHA-DAX-8 & $1 / 250$ & $17 \pm 1$ & $1.1 \pm 0.3$ & $17 \pm 4$ \\
\hline $\mathrm{S} 1-\mathrm{SRHA}-\mathrm{Al}_{2} \mathrm{O}_{3}$ & $1 / 12$ & $14 \pm 1$ & $6.1 \pm 0.8$ & $56 \pm 8$ \\
\hline $\mathrm{S} 2-\mathrm{SRHA}-\mathrm{Al}_{2} \mathrm{O}_{3}$ & $1 / 50$ & $2.03 \pm 0.03$ & $10.1 \pm 0.7$ & $94 \pm 4$ \\
\hline S1-PPHA-DAX-8 & $1 / 120$ & $13 \pm 2$ & $2.7 \pm 0.5$ & $38 \pm 6$ \\
\hline S2-PPHA-DAX-8 & $1 / 240$ & $11 \pm 1$ & $1.7 \pm 0.2$ & $56 \pm 7$ \\
\hline $\mathrm{S} 1-\mathrm{PPHA}-\mathrm{Al}_{2} \mathrm{O}_{3}$ & $1 / 12$ & $17.3 \pm 0.4$ & $11.3 \pm 0.3$ & $51 \pm 8$ \\
\hline S3-PPHA- $\mathrm{Al}_{2} \mathrm{O}_{3}$ & $1 / 50$ & $2.0 \pm 0.1$ & $6.1 \pm 0.3$ & $96 \pm 9$ \\
\hline S1-ESHA-DAX-8 & $1 / 80$ & $14.5 \pm 0.8$ & $3.8 \pm 0.2$ & $50 \pm 2$ \\
\hline S2-ESHA-DAX-8 & $1 / 160$ & $11.8 \pm 0.9$ & $3.0 \pm 0.2$ & $59 \pm 3$ \\
\hline $\mathrm{S} 1-\mathrm{ESHA}-\mathrm{Al}_{2} \mathrm{O}_{3}$ & $1 / 3$ & $41 \pm 2$ & $54 \pm 6$ & $28 \pm 3$ \\
\hline $\mathrm{S} 2-\mathrm{ESHA}-\mathrm{Al}_{2} \mathrm{O}_{3}$ & $1 / 6$ & $21 \pm 1$ & $38 \pm 1$ & $62 \pm 4$ \\
\hline
\end{tabular}


Table S-2. Exemplary DOC data obtained with the elemental analyzer and with UV-Vis spectroscopy at $254 \mathrm{~nm}$ for HA stock solutions $\left(\mathrm{HA}_{\text {stock }}\right)$ and the humic acid fraction remaining in solution after sorption to $\mathrm{Al}_{2} \mathrm{O}_{3}\left(\mathrm{HA}_{\mathrm{aq}}\right)$. SUVA 254 was calculated from UV-Vis absorbance at $254 \mathrm{~nm}$ and DOC determined by an elemental analyzer (mean value \pm one standard deviation; $\mathrm{n} \geq 3$ ). $\mathrm{HA} / \mathrm{Al}_{2} \mathrm{O}_{3}$ indicates the mass ratio of $\mathrm{HA}$ and $\mathrm{Al}_{2} \mathrm{O}_{3}$ present in the sorption batch experiments. \% sorbed HA is the percentage of sorbed HA based on the total amount of HA in the system. $\mathrm{HA}_{\mathrm{aq}}$ samples are highlighted in light green.

\begin{tabular}{|c|c|c|c|c|c|}
\hline $\begin{array}{l}\text { Experimental } \\
\text { Setup }\end{array}$ & $\begin{array}{c}\text { Mass } \\
\text { ratio } \\
\mathbf{H A} / \mathbf{A l}_{2} \mathbf{O}_{3}\end{array}$ & \% HAsorb & $\begin{array}{c}\text { DOC } \\
\text { elemental analyzer } \\
{[\mathrm{mg} \mathrm{C} / \mathrm{L}]}\end{array}$ & $\begin{array}{c}\text { DOC } \\
\text { UV-VIS 254 nm } \\
{[\mathrm{mg} \mathrm{C/L]}}\end{array}$ & $\begin{array}{c}\text { SUVA }_{254} \\
{\left[\mathrm{~L} \cdot\left(\mathrm{mg} \mathrm{C}^{-1} \cdot \mathrm{m}^{-1}\right]\right.}\end{array}$ \\
\hline SRHA $_{\text {stock }}$ & - & - & $4.0 \pm 0.3$ & - & $7.4 \pm 0.5$ \\
\hline $\mathrm{S} 1-\mathrm{SRHA}_{\mathrm{aq}}-\mathrm{Al}_{2} \mathrm{O}_{3}$ & $1 / 12$ & $56 \pm 8$ & $14 \pm 1$ & $12.6 \pm 0.1$ & $6.5 \pm 0.6$ \\
\hline $\mathrm{S} 2-\mathrm{SRHA}_{\mathrm{aq}}-\mathrm{Al}_{2} \mathrm{O}_{3}$ & $1 / 50$ & $94 \pm 4$ & $2.0 \pm 0.03$ & $0.3 \pm 0.1$ & $1.7 \pm 0.5$ \\
\hline PPHA stock & - & - & $4.1 \pm 0.2$ & - & $7.0 \pm 1$ \\
\hline $\mathrm{S} 1-\mathrm{PPHA} \mathrm{aq}_{\mathrm{aq}}-\mathrm{Al}_{2} \mathrm{O}_{3}$ & $1 / 12$ & $51 \pm 8$ & $17.3 \pm 0.4$ & $17.2 \pm 0.5$ & $7.0 \pm 2$ \\
\hline $\mathrm{S} 2-\mathrm{PPHA} \mathrm{aq}_{\mathrm{a}}-\mathrm{Al}_{2} \mathrm{O}_{3}$ & $1 / 50$ & $96 \pm 9$ & $2.0 \pm 0.1$ & $0.4 \pm 0.3$ & $5.0 \pm 1$ \\
\hline ESHA $_{\text {stock }}$ & - & - & $3.8 \pm 0.2$ & - & $7.9 \pm 0.5$ \\
\hline $\mathrm{S} 1-\mathrm{ESHA}_{\mathrm{aq}}-\mathrm{Al}_{2} \mathrm{O}_{3}$ & $1 / 3$ & $28 \pm 3$ & $41 \pm 2$ & $41 \pm 1$ & $7.8 \pm 0.2$ \\
\hline $\mathrm{S} 2-\mathrm{ESHA}_{\mathrm{aq}}-\mathrm{Al}_{2} \mathrm{O}_{3}$ & $1 / 6$ & $62 \pm 4$ & $21 \pm 1$ & $20.5 \pm 1$ & $7.5 \pm 0.4$ \\
\hline
\end{tabular}




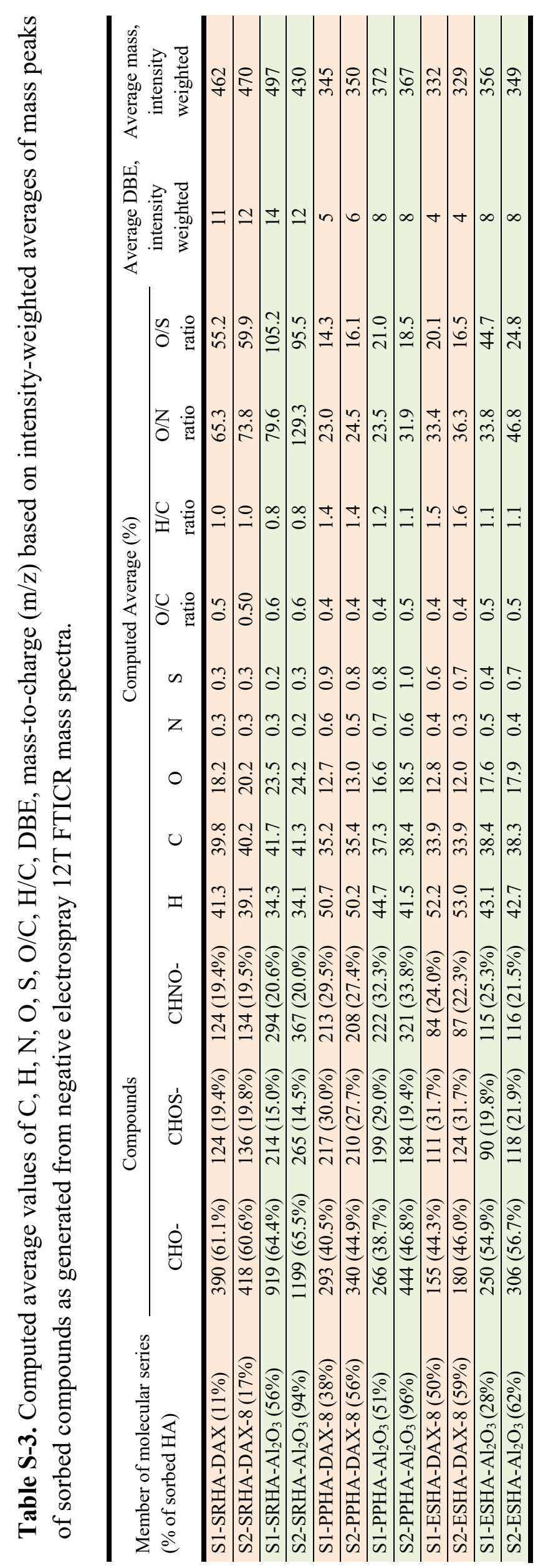


Figure S-1. Calibration curves for Total Organic Carbon (TOC) measurements of humic acid standards at pH 7 using UV-Vis spectroscopy at $254 \mathrm{~nm}$ : Suwanee River (SRHA, purple diamonds), Pahokee Peat (PPHA, yellow squares) and Elliott Soil (ESHA, green circles) humic acids.

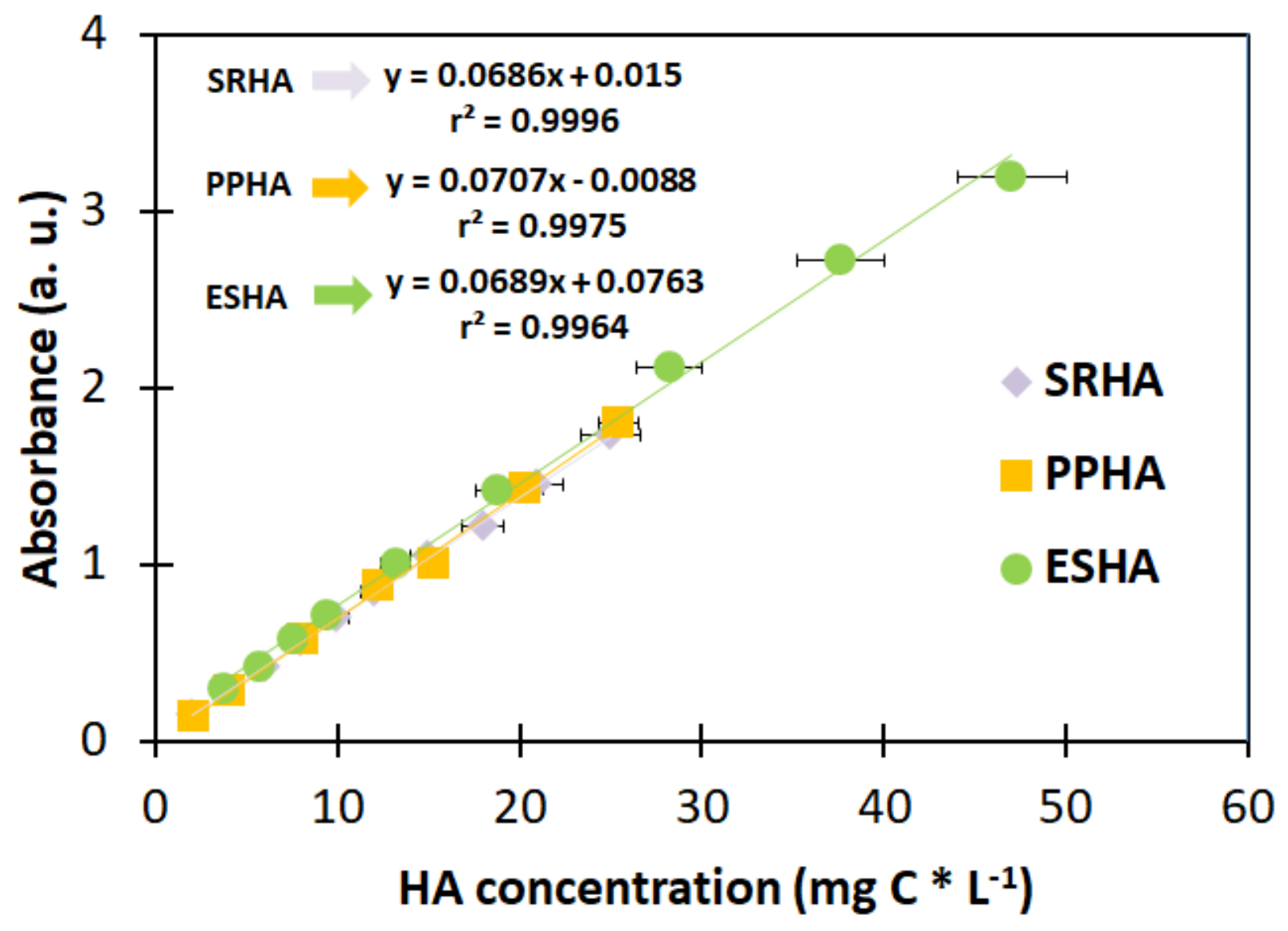


Figure S-2. Van Krevelen diagrams of the assigned molecular series (i.e., CHO, CHNO and CHOS) of Suwannee River Humic Acid (SRHA), Pahokee Peat Humic Acid (PPHA) and Elliott Soil Humic acid (ESHA) standard samples. Symbol color for compounds bearing combinations of $\mathrm{C}, \mathrm{H}, \mathrm{O}, \mathrm{N}$, and $\mathrm{S}$ atoms relates to: blue $(\mathrm{CHO})$, orange $(\mathrm{CHON})$, green (CHOS). Symbol areas reflect the relative intensities of each mass peak.
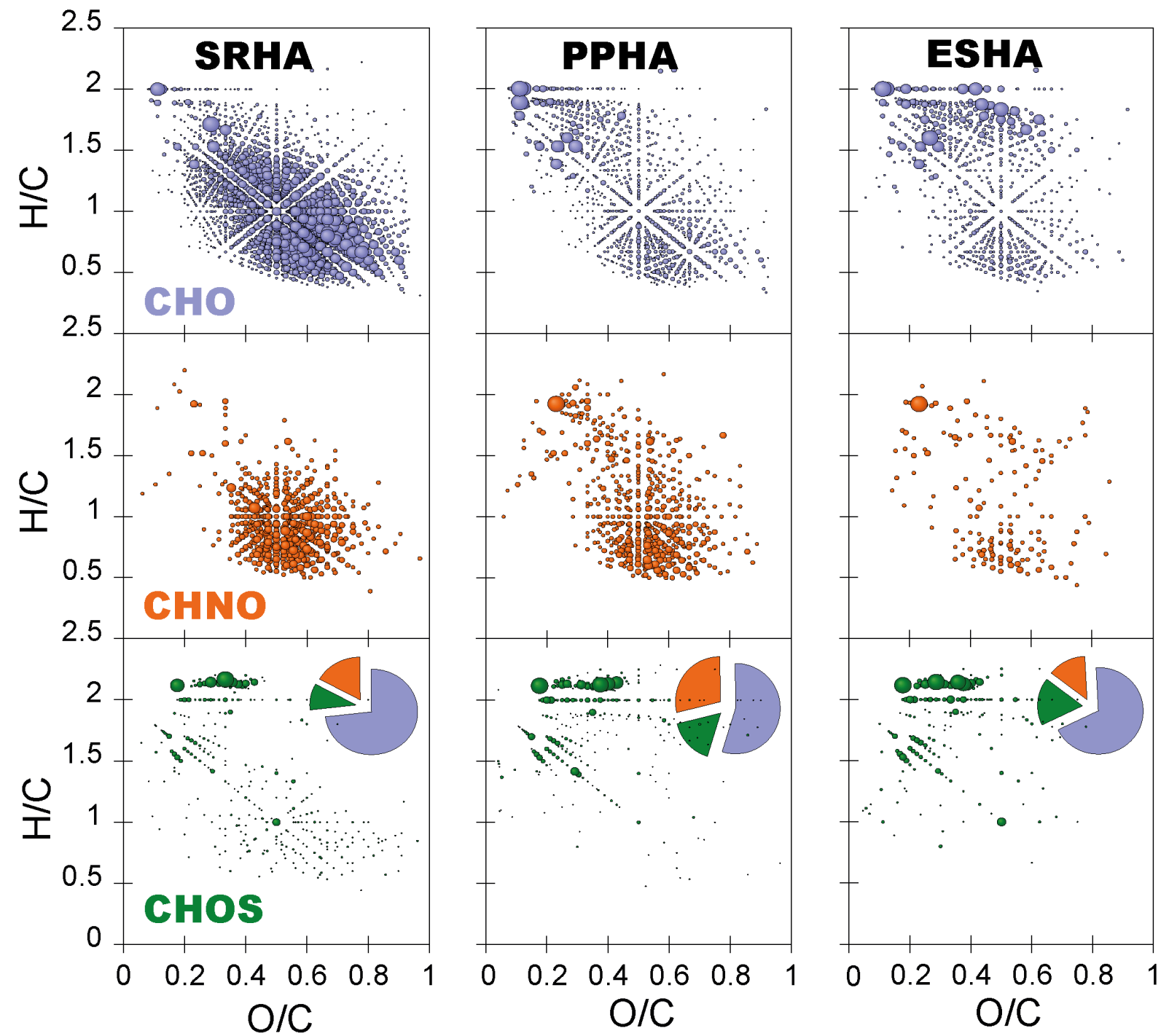
Figure S-3. Double bond equivalents (DBE) versus number of carbon atoms involved in $\mathrm{CHO}$, $\mathrm{CHNO}$ and CHOS molecular series of humic acid stock solutions $\left(\mathrm{HA}_{\text {stock}}\right)$ and the dissolved components remaining in solution after equilibration with $\mathrm{DAX}-8$ or $\mathrm{Al}_{2} \mathrm{O}_{3}$ sorbents. Color coded symbols for components bearing combinations of $\mathrm{C}, \mathrm{H}, \mathrm{O}, \mathrm{N}$, and $\mathrm{S}$ atoms refer to: blue (CHO), orange (CHNO), green (CHOS). The size of the symbols reflects relative intensities of each mass peak in the sample. Percentage (\%) values indicate the fraction of $\mathrm{HA}_{\text {stock }}$ remaining in solution after equilibration with the sorbents DAX-8 and $\mathrm{Al}_{2} \mathrm{O}_{3}$ (See also Figure 2).

\section{S-3a Suwannee River Humic Acid (SRHA)}

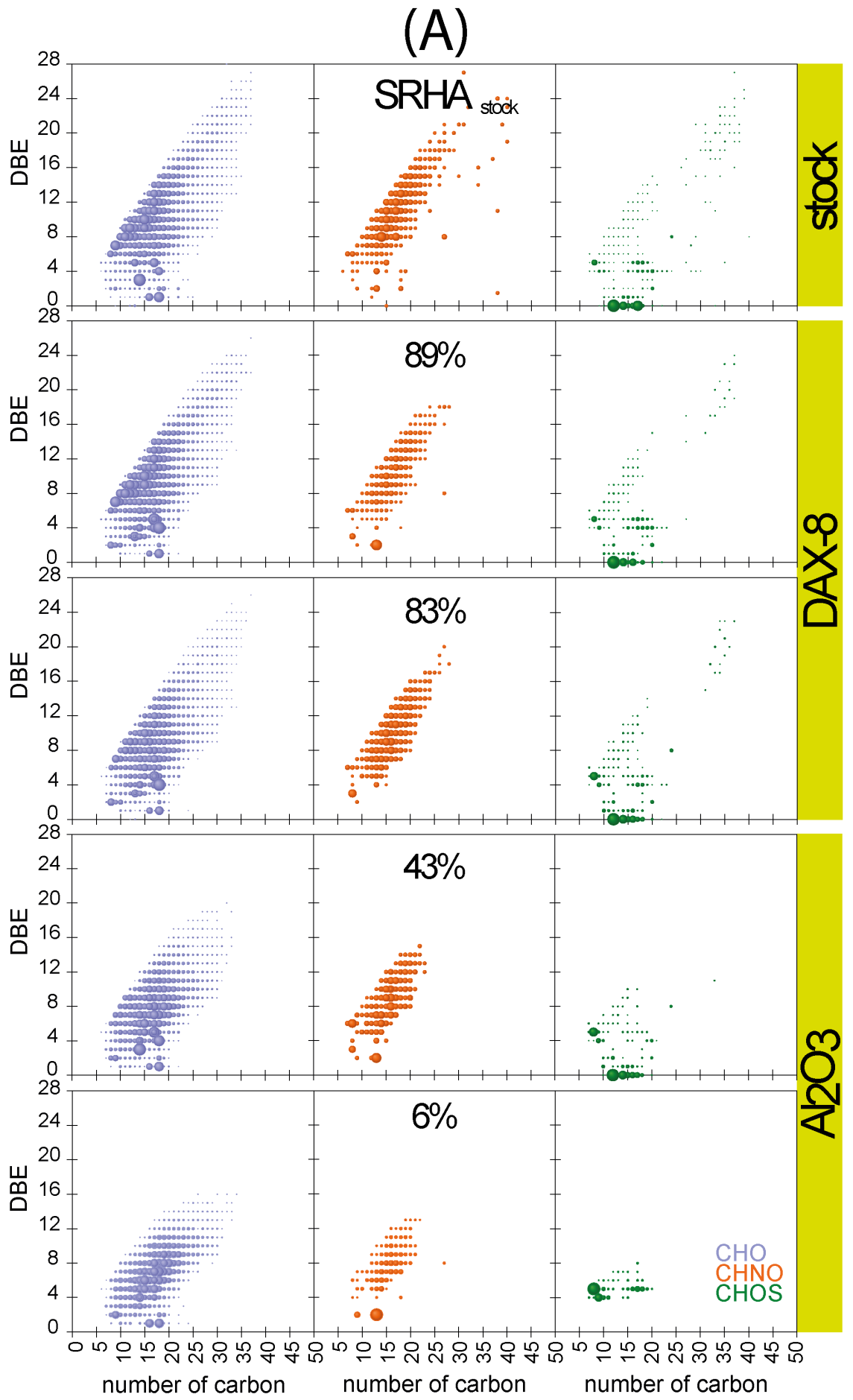

To be continued (Figure S-3) 
S-3b Pahokee Peat Humic Acid (PPHA)

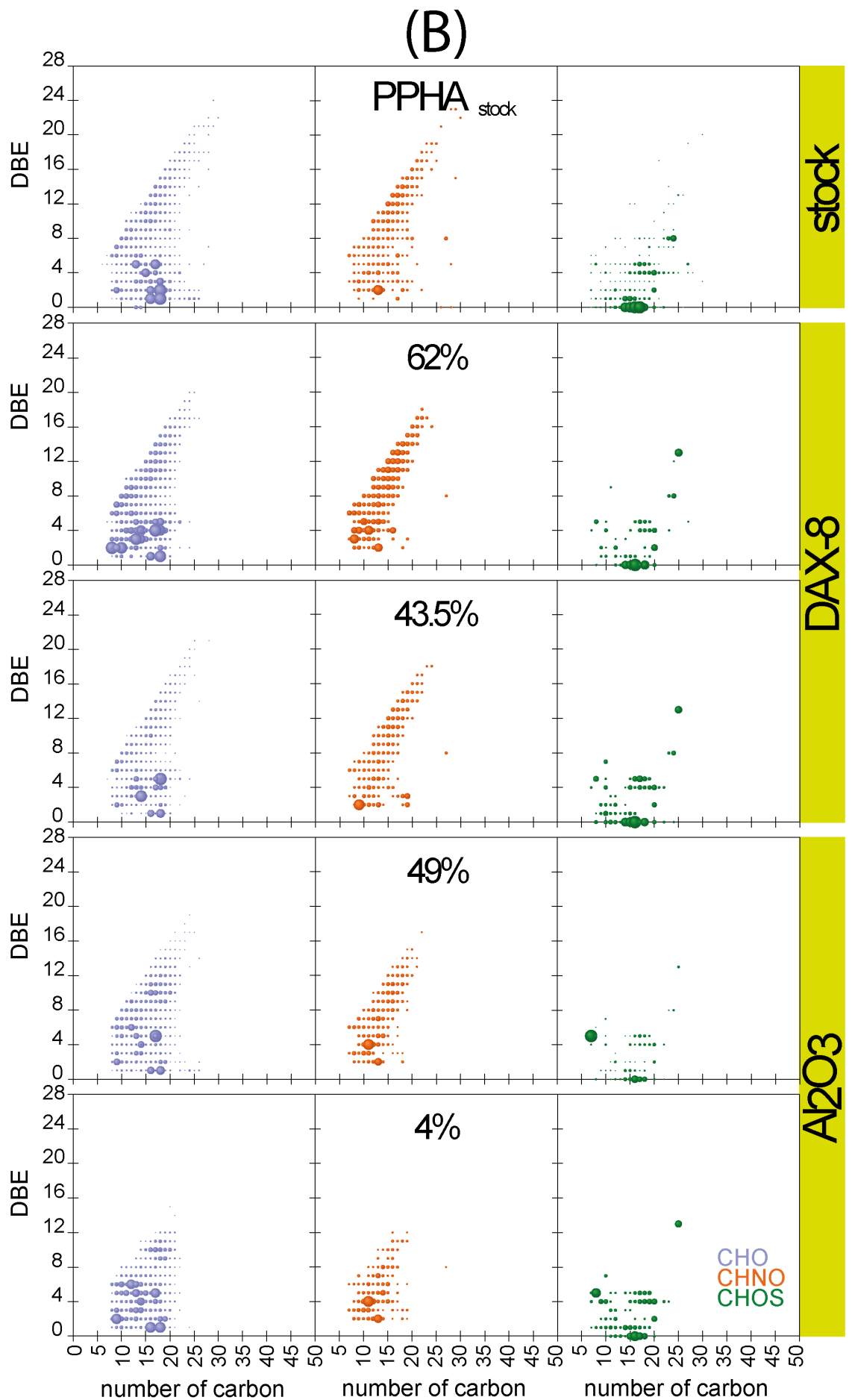

To be continued (Figure S-3) 
S-3c Elliott Soil Humic Acid (ESHA)

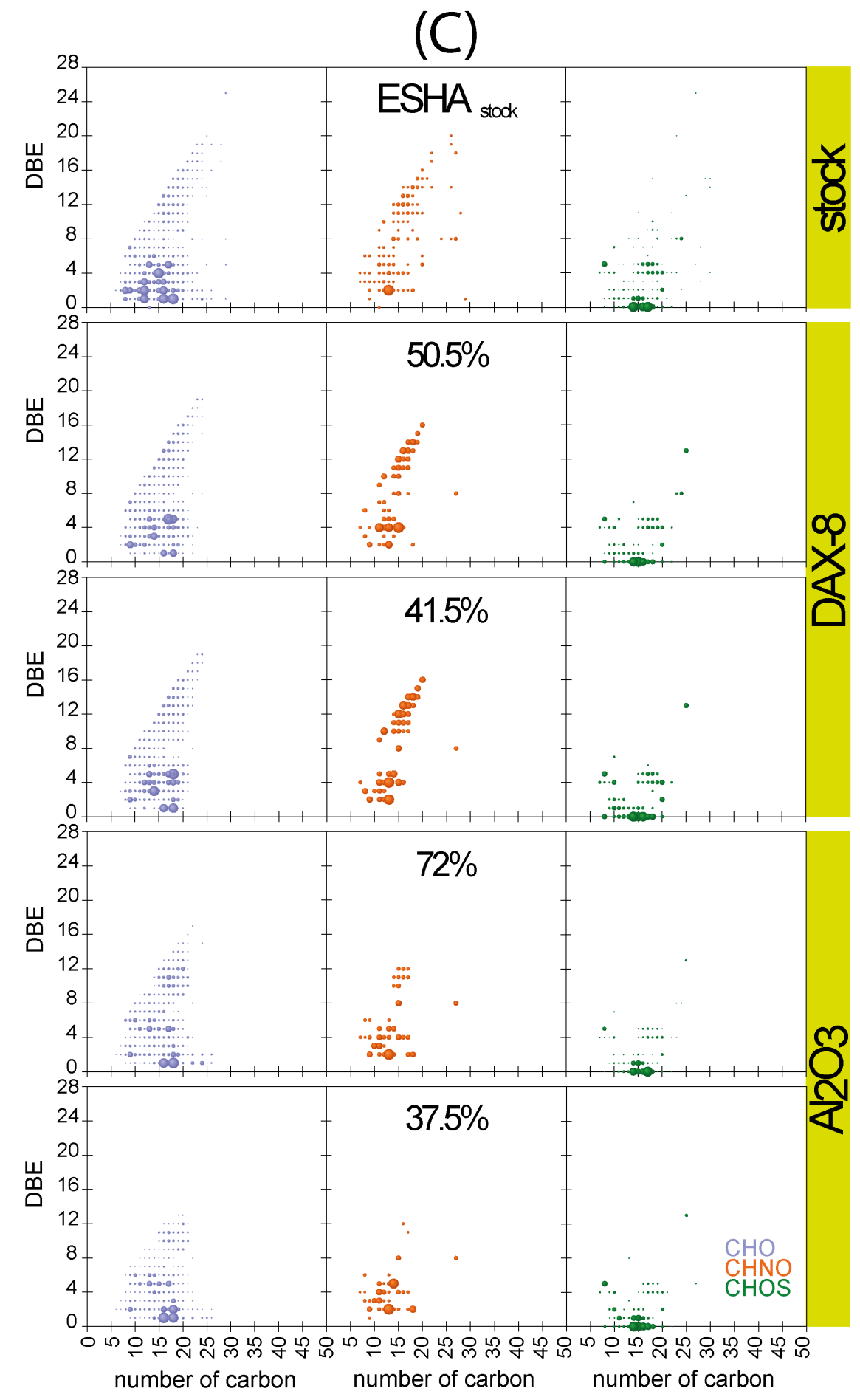


Figure S-4. Double bond equivalents (DBE) versus number (\#) of oxygen atoms involved in $\mathrm{CHO}, \mathrm{CHNO}$ and $\mathrm{CHOS}$ molecular series for humic acid stock solutions (A) and for the components remaining in solution after equilibration with DAX-8 (B) and $\mathrm{Al}_{2} \mathrm{O}_{3}(\mathrm{C})$ sorbents, respectively. Percentage (\%) values indicate the mass fraction of $\mathrm{HA}_{\text {stock }}$ remaining in solution after equilibration with $\mathrm{DAX}-8$ or $\mathrm{Al}_{2} \mathrm{O}_{3}$ sorbents.

\section{S-4a Suwannee River Humic Acid (SRHA)}

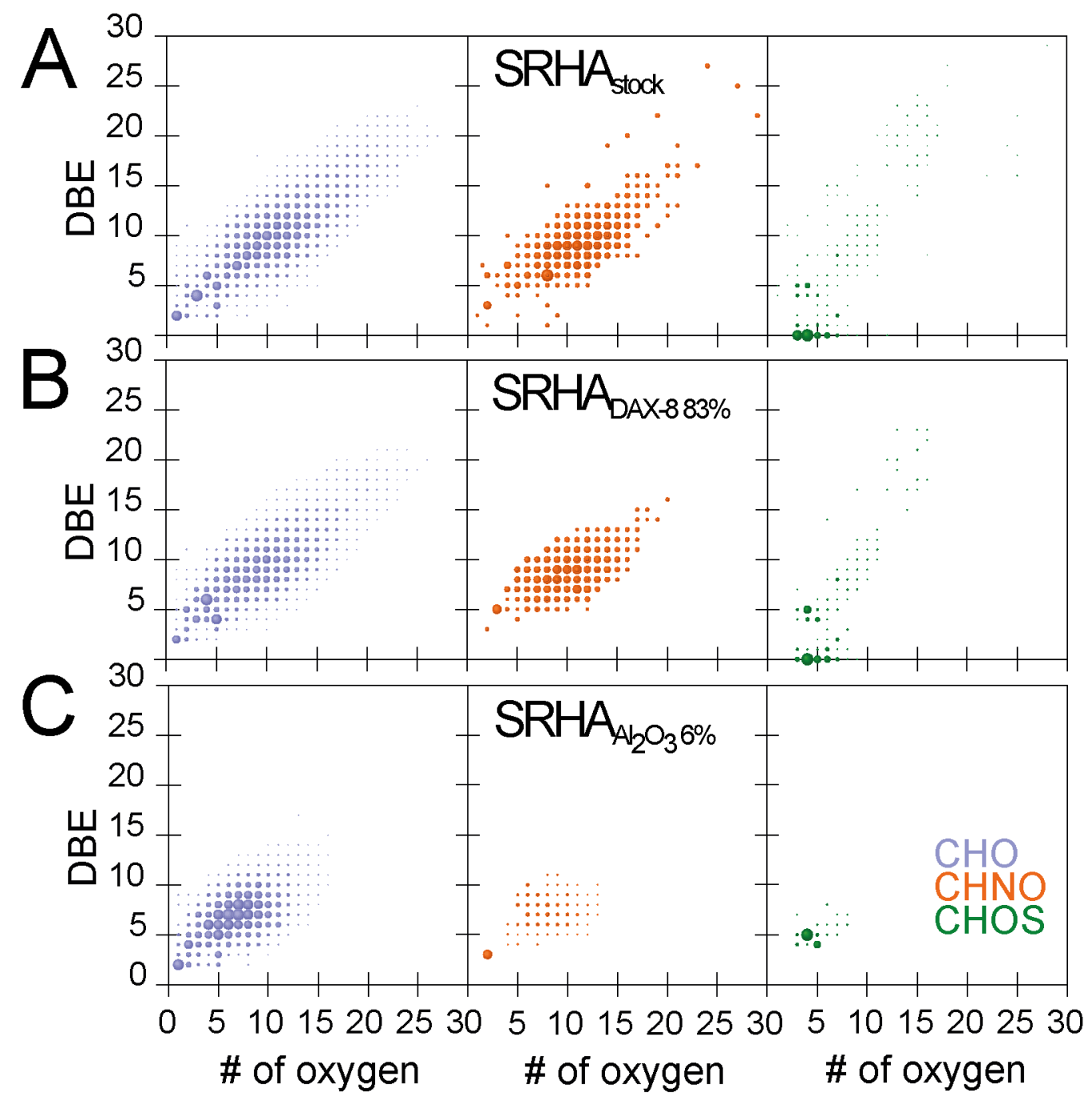

To be continued (Figure S-4) 
S-4b Pahokee Peat Humic Acid (PPHA)

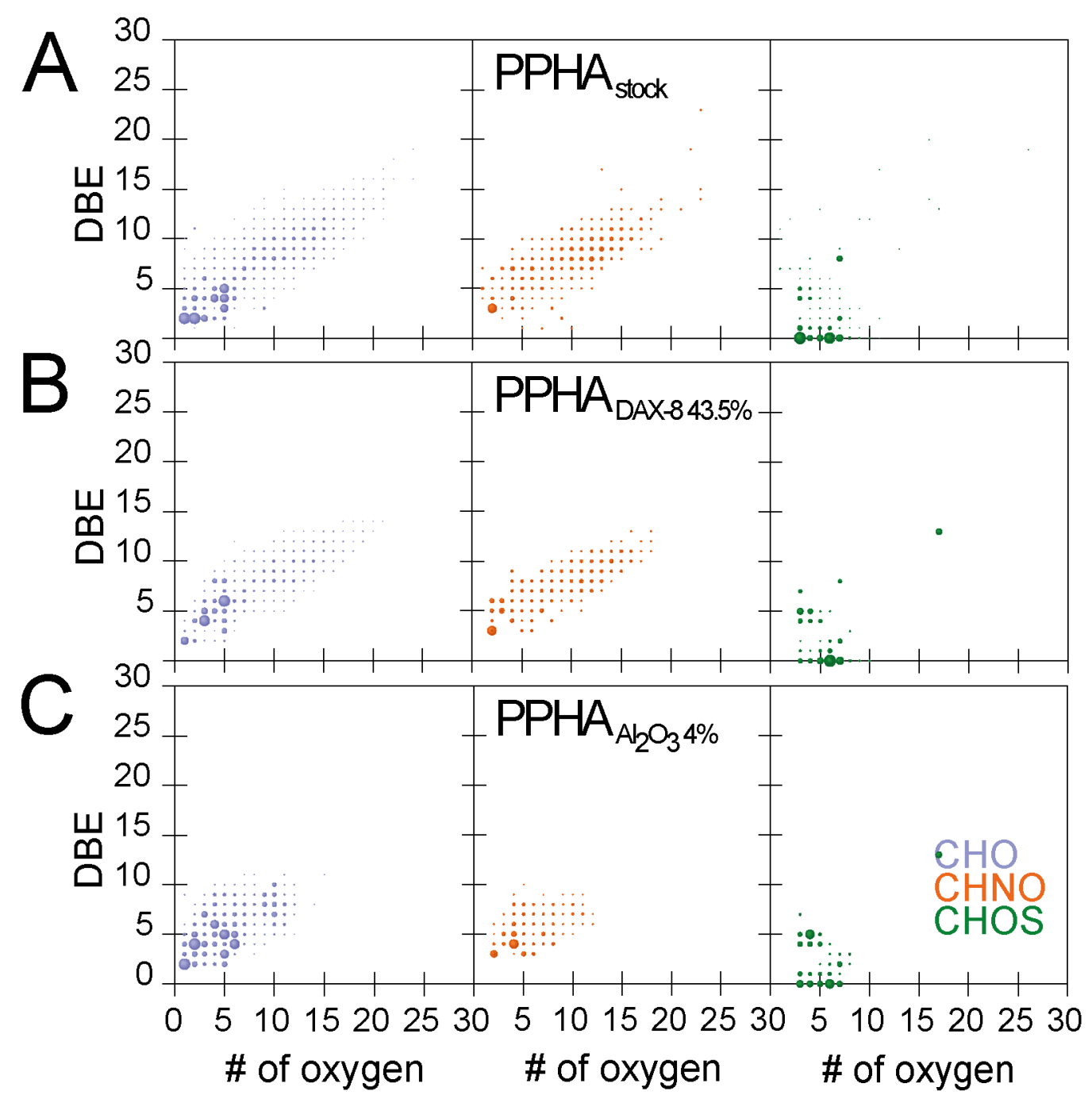

To be continued (Figure S-4) 
S-4c Elliott Soil Humic Acid (ESHA)

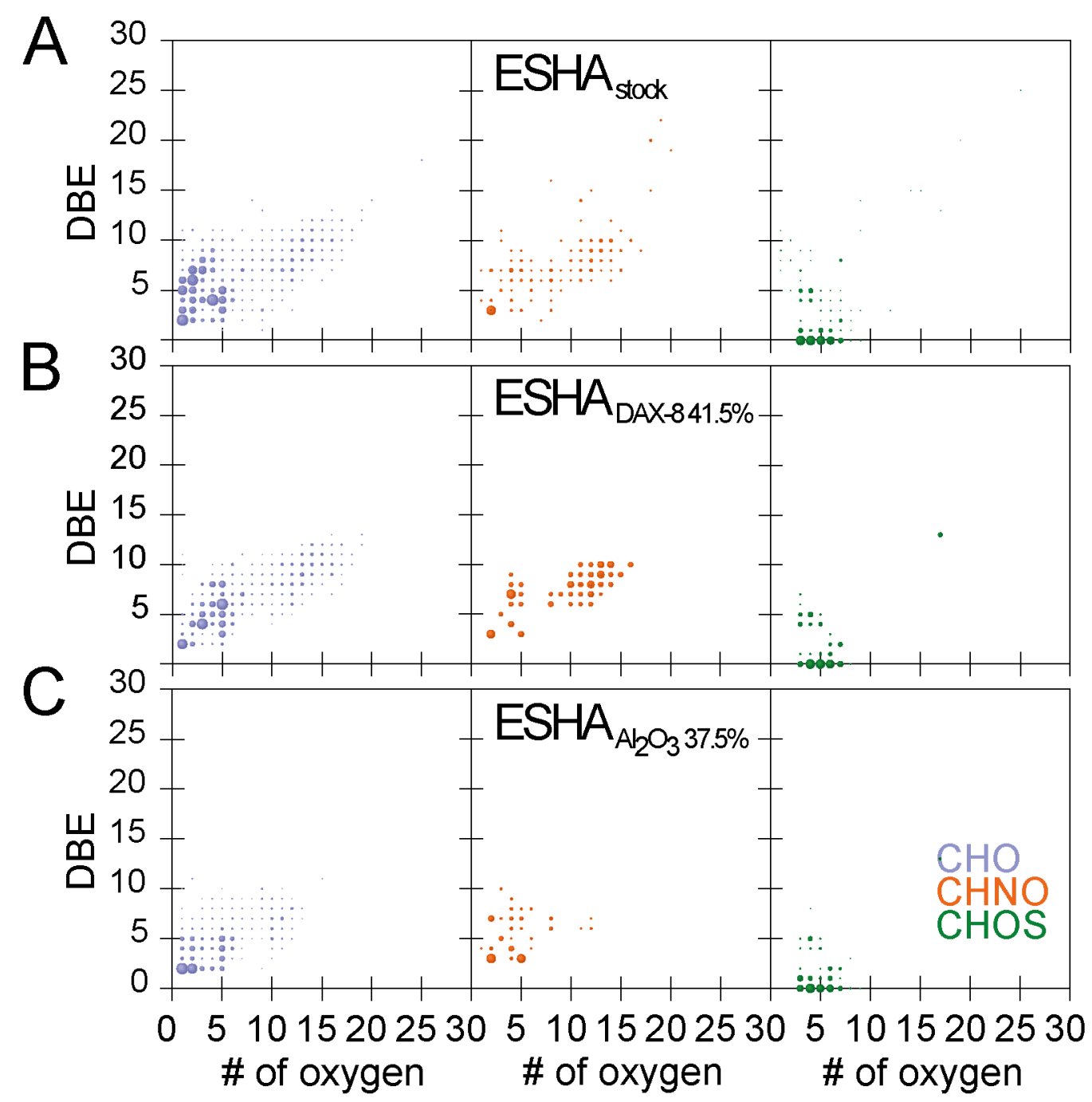


Figure S-5. Histograms showing counts of oxygen and carbon atoms versus assigned molecular compositions of Elliott Soil (ESHA), Pahokee Peat (PPHA) and Suwannee River (SRHA) humic acid samples. Blue bars refer to the respective stock solutions, orange bars to the components remaining in solution after sorption to DAX-8 resin and grey bars to the fraction remaining in solution after sorption to $\mathrm{Al}_{2} \mathrm{O}_{3}$. Percentage (\%) values indicate the mass fraction of $\mathrm{HA}_{\text {stock }}$ remaining in solution after equilibration with $\mathrm{DAX}-8$ or $\mathrm{Al}_{2} \mathrm{O}_{3}$ sorbents.
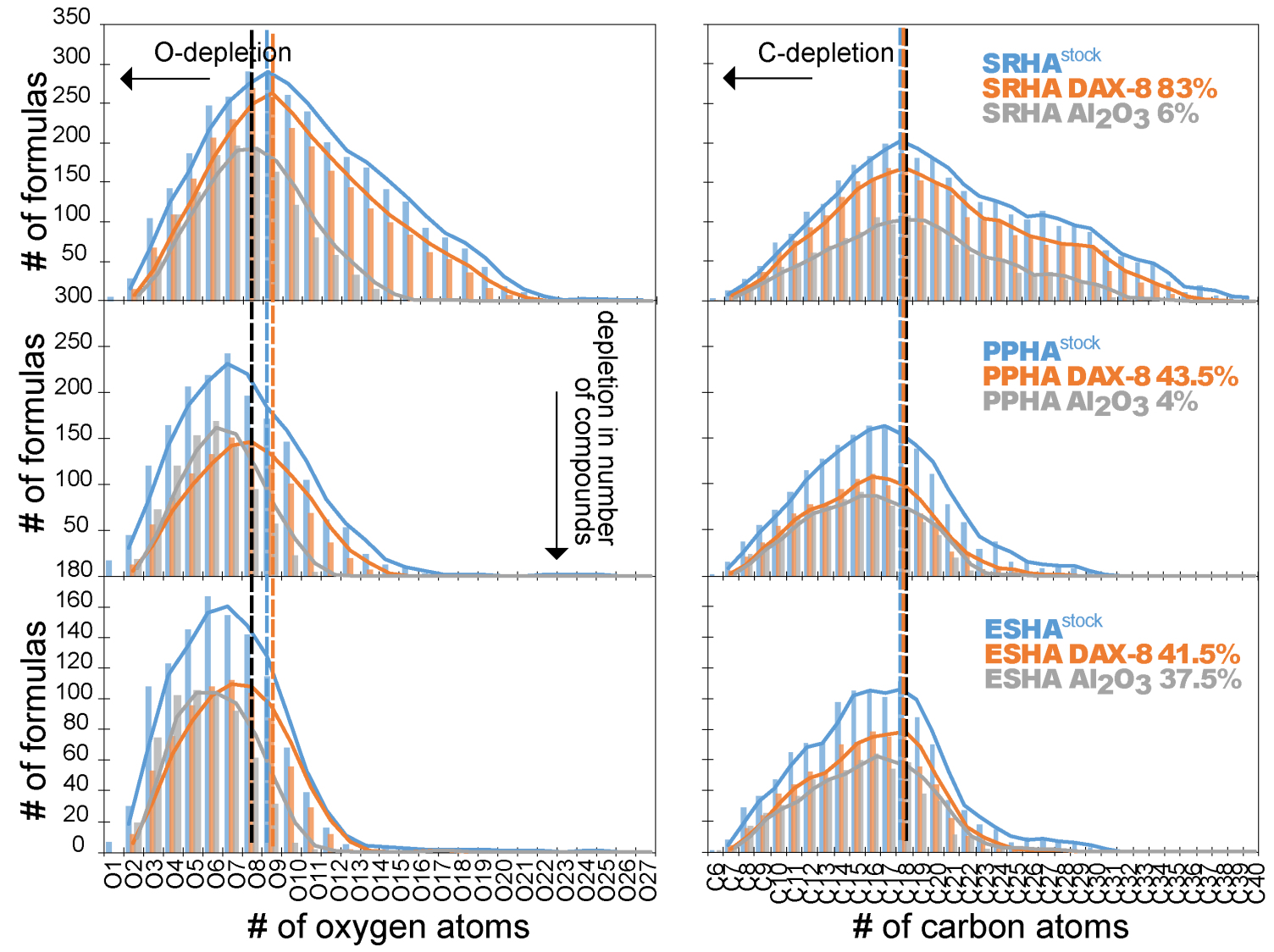
Figure S-6. Histograms showing counts of oxygen atoms of individual $\mathrm{CHO}$ molecular compositions of Elliott Soil (ESHA), Pahokee Peat (PPHA) and Suwannee River (SRHA) humic acid samples. Orange and grey bars refer to the components remaining in solution after sorption to DAX-8 resin and $\mathrm{Al}_{2} \mathrm{O}_{3}$, respectively. Percentage (\%) values indicate the mass fraction of $\mathrm{HA}_{\text {stock }}$ remaining in solution after equilibration with $\mathrm{DAX}-8$ or $\mathrm{Al}_{2} \mathrm{O}_{3}$ sorbents.

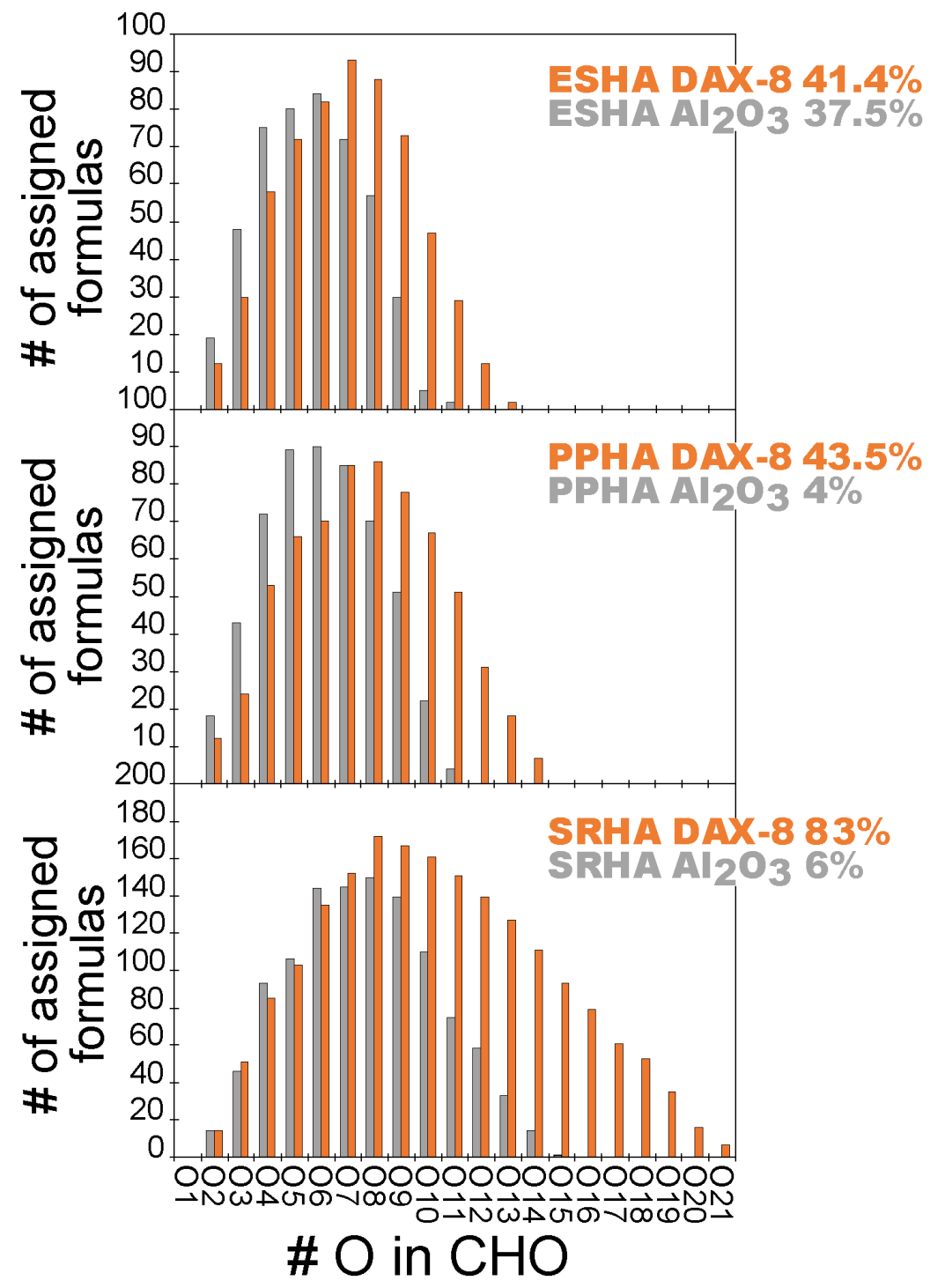


Figure S-7. Histograms showing counts of oxygen atoms of individual CHNO molecular compositions of Elliott Soil (ESHA), Pahokee Peat (PPHA) and Suwannee River (SRHA) humic acid samples. Orange and grey bars refer to the components remaining in solution after sorption to DAX-8 resin and $\mathrm{Al}_{2} \mathrm{O}_{3}$, respectively. Insert percentage (\%) values indicate the mass fraction of $\mathrm{HA}_{\text {stock }}$ remaining in solution after equilibration with $\mathrm{DAX}-8$ or $\mathrm{Al}_{2} \mathrm{O}_{3}$ sorbents.

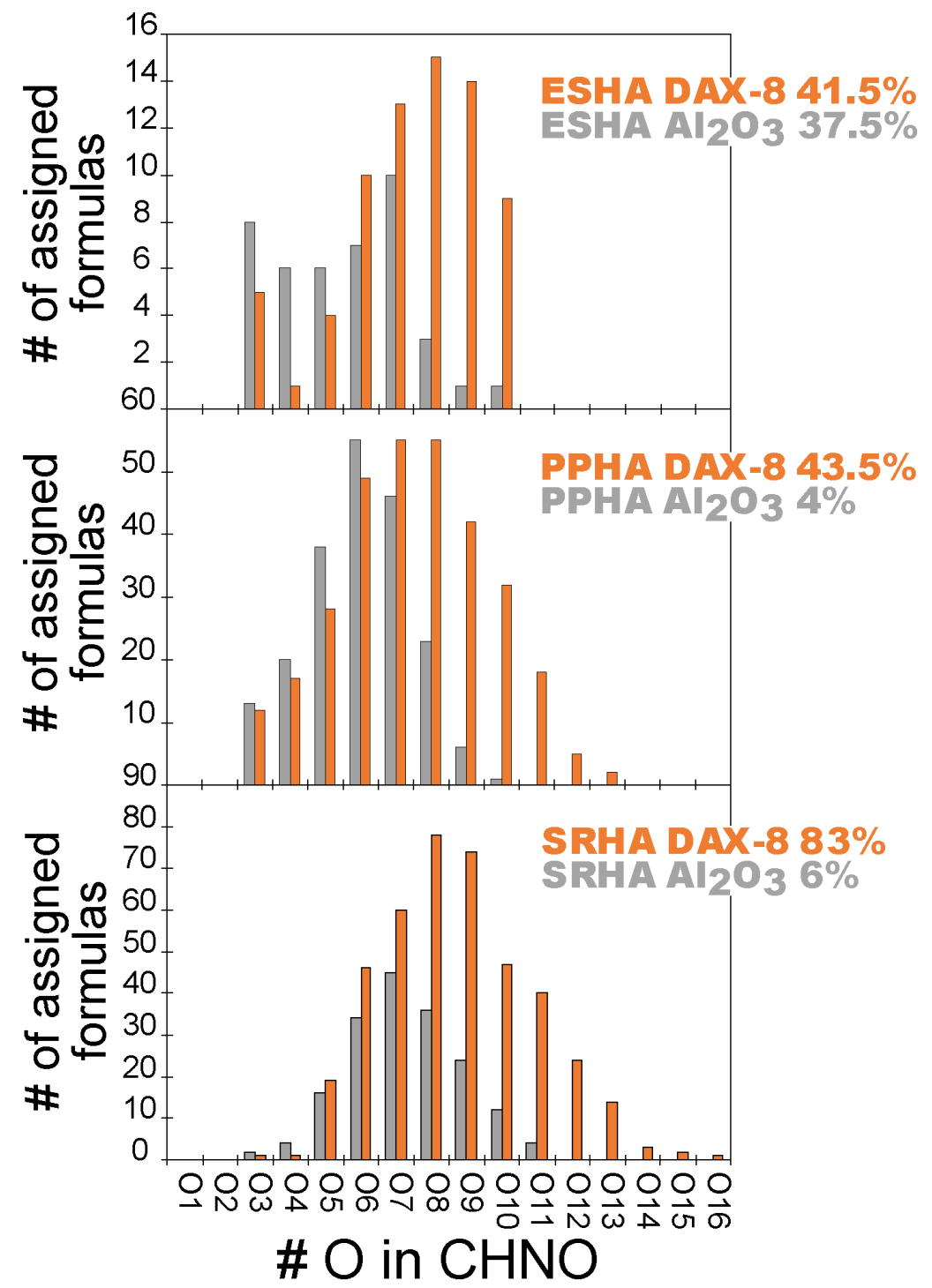


Figure S-8. Histograms showing counts of oxygen atoms of individual CHOS molecular compostions of Elliott Soil (ESHA), Pahokee Peat (PPHA) and Suwannee River (SRHA) humic acid samples. Orange and grey bars refer to the fraction remaining in solution after sorption to DAX-8 resin and $\mathrm{Al}_{2} \mathrm{O}_{3}$, respectively. Insert percentage (\%) values indicate the fraction of $\mathrm{HA}_{\text {stock }}$ remaining in solution after equilibration with $\mathrm{DAX}-8$ or $\mathrm{Al}_{2} \mathrm{O}_{3}$ sorbents.

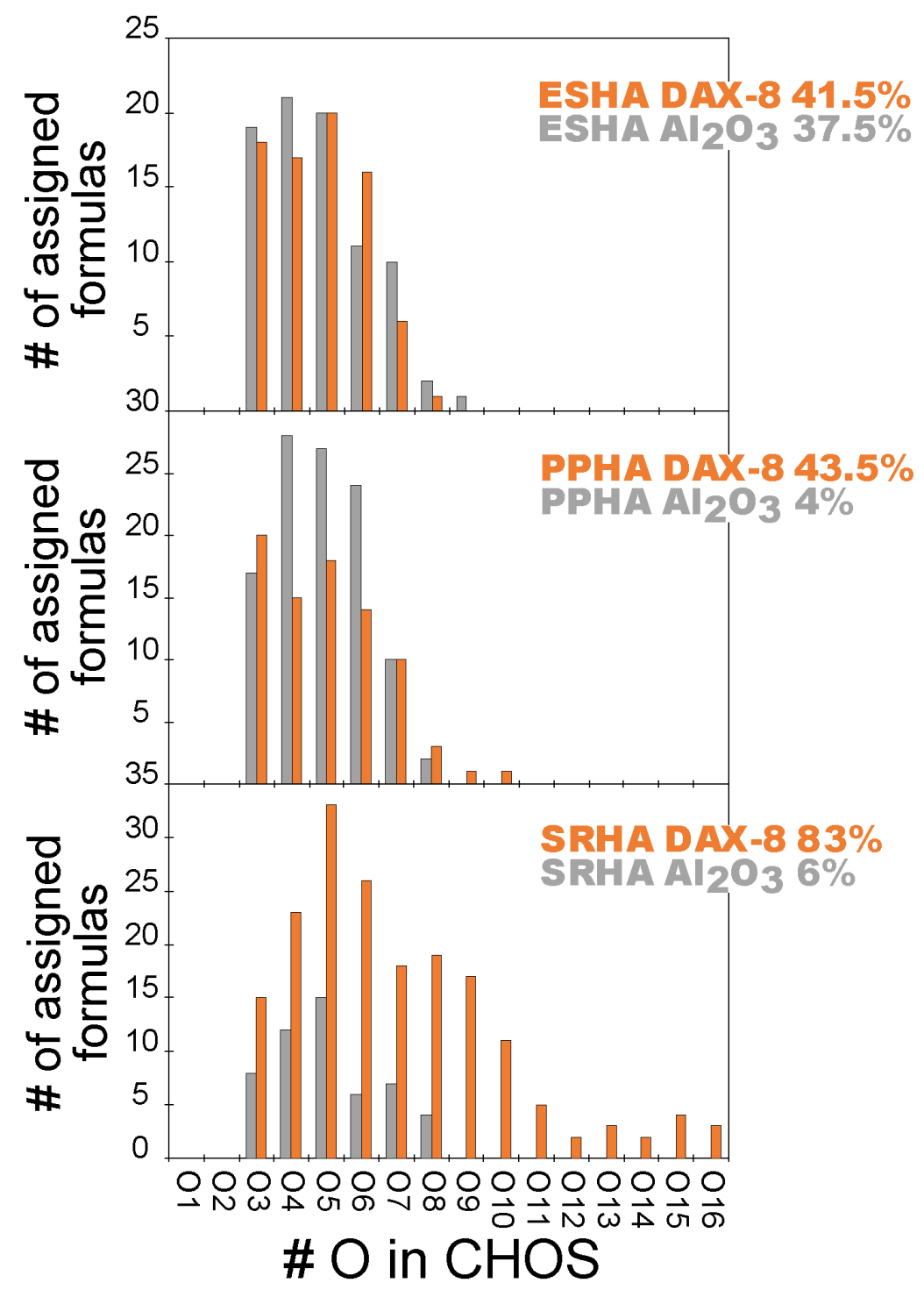


Figure S-9. Similarity plot based on negative electrospray 12T FTICR mass spectra comparing the composition of humic acids solutions before (stock solutions) and after sorption to DAX-8 and $\mathrm{Al}_{2} \mathrm{O}_{3}$ sorbents at $\mathrm{pH}=7$. The clustering diagram is based on the similarity values between the spectra of the samples using Pearson's correlation coefficient.

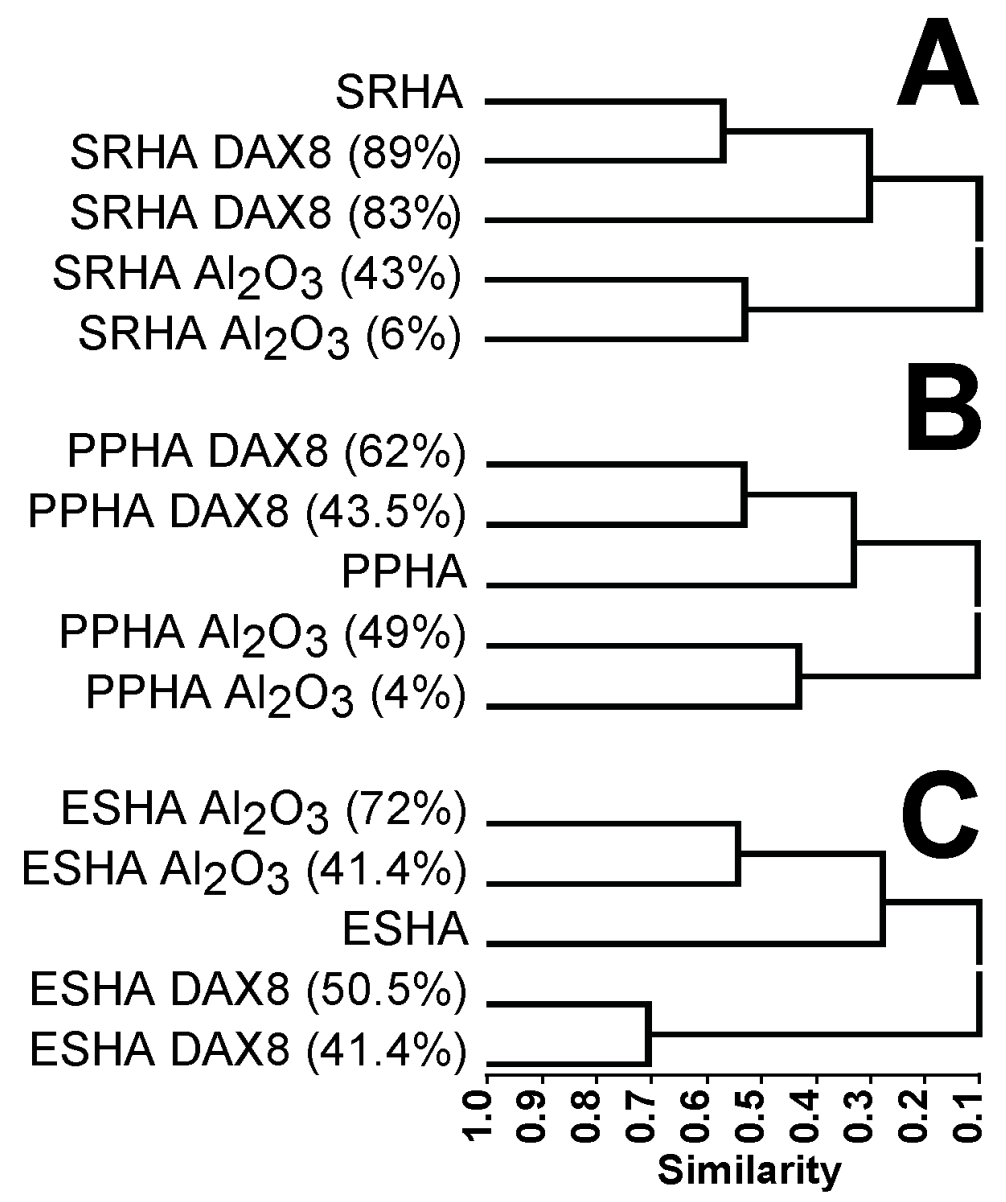

